\title{
Victimization and Perpetration of Intimate Partner Violence among Female and Male Youth and Adults in South Africa
}

\author{
Karl Peltzer ${ }^{1,2}$, Nancy Phaswana-Mafuya ${ }^{1,3,4}$ \& Supa Pengpid ${ }^{2,5}$ \\ ${ }^{1}$ HIV/AIDS/STIs and TB Research Programme, Human Sciences Research Council, Pretoria, South Africa \\ ${ }^{2}$ Department of Research \& Innovation, University of Limpopo, Turfloop, South Africa \\ ${ }^{3}$ Department of Social Work, University of Limpopo, Turfloop, South Africa \\ ${ }^{4}$ Office of the Deputy Vice Chancellor: Research \& Engagement, Nelson Mandela Metropolitan University, Port \\ Elizabeth, South Africa \\ ${ }^{5}$ ASEAN Institute for Health Development, Mahidol University, Salaya, Thailand \\ Correspondence: Karl Peltzer, HIV/AIDS/STIs and TB Research Programme, Human Sciences Research Council; \\ Private Bag X41, Pretoria 0001, South Africa. Tel: 27-12-302-2000. E-mail: kpeltzer@hsrc.ac.za
}

Received: June 1, 2017 Accepted: June 19, 2017 Online Published: August 4, 2017

doi:10.5539/gjhs.v9n10p1 URL: https://doi.org/10.5539/gjhs.v9n10p1

\begin{abstract}
Objective: Intimate partner violence (IPV) is a huge public health problem. The aim of the study was to estimate the prevalence and influence of sociodemographic and health characteristics on IPV victimization and perpetration among women and men 15 years and older in South Africa.

Materials and Methods: Data based on the South African national population-based survey in 2012 for 15916 (8532 women and $7384 \mathrm{men}$ ) aged 15 years and older who were in an intimate partner relationship were analysed. Bivariate and multivariable logistic regression was conducted to assess the association between sociodemographic factors, health variables and IPV victimization and perpetration.
\end{abstract}

Results: Among women, $8.5 \%$ had experienced any form of IPV in the past 12 months, and $3.5 \%$ of the women had engaged in IPV perpetration in the past 12 months. Among men, 5.0\% had experienced any form of IPV in past 12 months, and 4.4\% of the men had engaged in IPV perpetration in the past 12 months. In multivariable logistic regression analysis among women, younger age, being African Black, having psychological distress, having been a victim of violent crime and having had multiple sexual partners were associated with IPV victimization in the past 12 months, while younger age, psychological distress, hazardous or harmful alcohol use, and having had multiple sexual partners was associated with IPV perpetration in the past 12 months. In multivariable logistic regression analysis among men, younger age, psychological distress, hazardous or harmful alcohol use, and having been a victim of violence crime was associated with IPV victimization in the past 12 months, while younger age, poor health status, psychological distress, hazardous or harmful alcohol use, and illicit drug use was associated with IPV perpetration in the past 12 months.

Conclusion: Past 12-month prevalence of IPV victimization and perpetration among women and men was significant. IPV gender commonalities and differences in risk factors, such as psychological distress, substance use, crime victimization and sexual risk behaviour, may inform strategies of violence prevention programmes.

Keywords: Intimate partner violence, victimization, perpetration, women, men, risk factor, South Africa, national survey

\section{Introduction}

Intimate partner violence (IPV) refers to "behaviour by an intimate partner or ex-partner that causes physical, sexual or psychological harm, including physical aggression, sexual coercion, and psychological abuse and controlling behaviours." (WHO, 2016, p.1); a person can be a victim or perpetrator of IPV (WHO, 2013). Globally, IPV is a huge public health problem, especially in lower resourced countries (WHO, 2013). The past 12-month prevalence of IPV victimization among women seem to range between less than $4 \%$ in many high-income countries and $40 \%$ in some lower income countries (Heise \& Kotsadam, 2015). In the United States, the past 12 -month prevalence of severe IPV victimization was $2.3 \%$ among women and $2.1 \%$ among men (Breiding et al., 
2014). Regarding IPV perpetration, a study in eight developing countries found across countries that $31 \%$ of men reported IPV perpetration in their lifetime (Fleming et al., 2015). IPV has a range of negative health impacts, including injury, unintended pregnancy, sexually transmitted infections (STIs), poor mental health, and addiction (Campbell, 2002; Ellsberg et al., 2008).

"Population-level surveys based on reports from victims provide the most accurate estimates of the prevalence of intimate partner violence and sexual violence in non-conflict settings." (WHO, 2016, p.1). Based on a national population-based study in South Africa in 2002-2004 , the prevalence of IPV victimization (in their "current or most recent marriage or cohabiting relationship") was $29.3 \%$ among women and $20.9 \%$ among men, and IPV perpetration was $25.2 \%$ among women and $26.5 \%$ among men (Gass, Stein, Williams, \& Seedat, 2011). The prevalence of IPV perpetration among 15-19 year-old male youth in Johannesburg in South Africa was 40\% (Peitzmeier et al., 2016). In the 2016 Demographic and Health Survey in South Africa, the 12 months prevalence of physical IPV and sexual IPY victimization was among women $8 \%$ and $2 \%$, respectively (Statistics South Africa, 2017). In relation to violence and injuries in general in South Africa, they are the "second leading cause of death and loss of disability-adjusted life years" and "the rate of homicide of women by intimate partners is six times the global average" (Seedat et al., 2009, p.1011). According to Seedat et al. (2009, p.1011), "The social dynamics that support violence are widespread poverty, unemployment, and income inequality; patriarchal notions of masculinity that valourise toughness, risk-taking, and defence of honour; exposure to abuse in childhood and weak parenting; access to firearms; widespread alcohol misuse; and weaknesses in the mechanisms of law enforcement."

A number of studies found that there are multiple factors that contribute to IPV and sexual violence. The factors can be perpetrator-related, victim-related or both perpetrator and victim related (WHO, 2016, p.1; Gass et al., 2011; Heise \& Kotsadam, 2015). Sexual IPV perpetration and experience factors include: "lower levels of education; exposure to child maltreatment; witnessing family violence; harmful use of alcohol and attitudes that are accepting of violence and gender inequality"; perpetration factors include "antisocial personality disorder, having multiple partners or suspected by their partners of infidelity." (WHO, 2016, p.1; Gass et al., 2011; Heise \& Kotsadam, 2015).

Women are more likely to report IPV experiences than men are, and men are more likely to report IPV perpetration than women (Gass et al., 2011; Statistics South Africa, 2017). In addition to substance use disorders (Gass et al., 2011; Gonzalez, Connell, Businelle, Jennings, \& Chartier, 2014; Peitzmeier et al. 2016), IPV experiences and/or perpetration among women and/or men is associated with common mental disorders and/or community violence victimization (Fleming et al. 2015; Gass et al., 2011, Ishida, Stupp, Melian, Serbanescu, \& Goodwin, 2010; Peitzmeier et al. 2016).

There is a lack of more recent nationally representative population-based surveys on IPV victimization and IPV perpetration in South Africa. The aim of the study was to estimate the prevalence and influence of sociodemographic and health characteristics on IPV victimization and perpetration among women and men 15 years and older in South Africa. Research questions included, what is the prevalence of IPV victimization and perpetration among women and men 15 years and older? and what are factors associated with IPV victimization and perpetration among women and men 15 years and older?

\section{Methods}

\subsection{Data and Sampling}

Secondary data analysis was conducted utilizing cross-sectional data from the "South African national HIV prevalence, incidence, and behaviour survey" from 2012 (Shisana et al., 2014). The sampling strategy was stratified by province, type of geolocality, and predominant population or racial groups. Using multistage sampling, a random sample of "enumeration areas" (EAs) was selected, and within EAs households were randomly selected. All individuals within a household were eligible to participate. Trained and supervised field workers interview-administered a questionnaire. Written informed consent was attained prior to the interview. The detailed survey methods are described elsewhere (Shisana et al., 2014).

This analysis is based only on data on 15 years and older individuals who indicated that they are in an intimate relationship who participated in the survey. The study survey proposal was approved by the "HSRC Research Ethics Committee (REC: 5/17/11/10)" and by the "Centers for Disease Control and Prevention" (CDC).

\subsection{Measures}

The questionnaire used included sections on intimate partner violence, sociodemograohic characteristis, health status variables, and health risk behaviour. 


\subsection{Intimate Partner Violence}

Participants who conceded that they were in an intimate relationship responded to seven IPV questions: "1) In the past 12 months, a partner has hit me (with a fist or slap or something else that could hurt me). 2) In the past 12 months, I have hit a partner (with a fist or slap or something else that could hurt them). 3) In the past 12 months, a partner has forced me to have sex against my wishes by using violence or threatening violence. 4) In the past 12 months, I have forced a partner to have sex with me when he/she didn't want it. 5) In the past 12 months, a partner has been violent towards me when he/she was drunk. 6) In the past 12 months, a partner has refused to use a condom during sex, even when I said I wanted to use one. 7) In the past year, have you been to a doctor, hospital or clinic for treatment because you have been injured by a partner?" (Response options were "yes"and "no") (Shisana et al., 2014).

Demographic measures included age, educational level, race (Black Africans or other races), and employment status.

\subsection{Self-Rated Health Status}

"In general, would you say that your health is excellent, good, fair or poor?" (Shisana et al., 2014). The response was dichotomized into $1=$ fair or poor and $0=$ excellent or good.

Psychological distress was measured with the "Kessler Psychological Distress Scale (K-10)" (Kessler et al., 2003). The 10-item scale assesses global psychological distress experienced in the past 30 days, e.g., "In the past 30 days, how often did you feel so restless that you could not sit still?" Response options ranged from $1=$ "none of the time" to $5=$ "all the time". These scores were added-up, with higher total scores indicating higher psychological distress (Kessler et al., 2003). A cut-off of 16 scores and more for detecting depression and anxiety disorders was used, as suggested in a previous validation study of the K-10 in the general population in South Africa (Andersen, Grimsrud, Myer, Williams, Stein, \& Seedat, 2011). Cronbach alpha for the K-10 in this sample was 0.89.

Hazardous or harmful alcohol use was assessed with the 10-item "Alcohol Disorder Identification Test (AUDIT)", e.g., "How often did you have a drink containing alcohol in the past 12 months?" (Babor, Higgins-Biddle, Saunders, \& Monteiro, 2001). Response options range from 0 to 4 , with a total range from 0 to 40 scores; a score of 8 or more indicated hazardous or harmful or probable dependent drinking (Babor et al., 2001). Cronbach alpha for the AUDIT in this sample was 0.84 .

Illicit drug use in the past three months was assessed with nine items of the "Alcohol, Smoking and Substance Involvement Screening Test (ASSIST)", e.g., "In the past three months, how often have you used cannabis (dagga, marijuana, pot, grass, hash, etc.?" (Humeniuk, Henry-Edwards, Ali, Poznyak, \& Monteiro, 2010). Response options ranged from $1=$ never to $5=$ almost daily. Any illicit drug use in the past three months was coded as 1 and never as 0 . All items were added together to indicate the prevalence of any illicit drug use in the past three months. Cronbach alpha for this section of the ASSIST in this sample was 0.61 .

Violent crime victimization was assessed with the question, "In the past 12 months, have you been a victim of a violent crime where a gun or knife was used to threaten or harm you?" (Response option was "yes" or "no") (Shisana et al., 2014).

Sexual risk behaviour was assessed with two questions,"Overall, how many sexual partners did you have during the past 12 months?" (Coded two or more=1 and 0 to 1 sexual partner $=0$ ) and "In the past six months, how many sex partners have you had whose HIV status you did not know at the time that you had sex?" (Coded 1 or more=1 and none $=0$ ) (Shisana et al., 2014).

\subsection{Data Analysis}

Descriptive statistics were used to summarize IPV prevalence, sociodemographic factors, and health characteristics. Pearson chi-square tests were used for differences in proportions. Associations between the outcome variables of IPV victimization and perpetration and sociodemographic and health independent variables were examined by calculating odds ratios (OR). Unconditional multivariable logistic regression was utilized to assess the impact of explanatory variables for the outcomes of IPV victimization and perpetration prevalence, for women and men separately. Variables that were found statistically significant at the $\mathrm{P}<.05$ levels in bivariate analyses were subsequently included in the multivariable models. In the analysis, weighted percentages have been reported. The "svy" command was utilized to take into account the multi-stage cluster design of the survey. All statistical analyses were performed using Stata software version 12 (Stata Corp., College Station, TX, USA). 


\section{Results}

\subsection{Descriptive Analysis}

\section{Sample characteristics}

Response rates for the interview was $89.5 \%$ (Shisana et al., 2014). The total sample included 15916 persons 15 years and older ( 8532 women and $7384 \mathrm{men}$ ) who indicated that they are currently in an intimate relationship. Almost half (45.8\%) had Grade 12 or more education, $76.1 \%$ were from the African Black population group and $48.5 \%$ were employed. Almost one in five (17.7\%) indicated that their health status was fair or poor, $36.2 \%$ had psychological distress, $12.6 \%$ engaged in hazardous or harmful drinking, $6.2 \%$ in illicit drug use in the past three months, and $8.9 \%$ were a victim of a violent crime in the past 12 months. Regarding HIV risk behaviour, $11.4 \%$ had multiple sexual partners in the past 12 months, and 27.1\% had sex with someone with unknown HIV status in the past 6 months. Some of the indicators assessed differed by gender, men were older and more often employed than women. While women had a higher prevalence of psychological distress han men, men engaged more often then women in hazardous or harmful alcohol use, illicit drug use, were victims of a violent crime, and had multiple sexual partners) (see Table 1).

Table 1. Sample Characteristics

\begin{tabular}{|c|c|c|c|c|}
\hline \multirow[t]{2}{*}{ Variable } & $\begin{array}{l}\text { All } \\
(n=15916)\end{array}$ & $\begin{array}{l}\text { Women } \\
(\mathrm{n}=8532)\end{array}$ & $\begin{array}{l}\text { Men } \\
(n=7384)\end{array}$ & \multirow{2}{*}{$\begin{array}{l}\text { Test statistic } \\
\text { P-value }\end{array}$} \\
\hline & $\mathrm{N}(\%)$ & $\mathrm{n}(\%)$ & $\mathrm{n}(\%)$ & \\
\hline \multicolumn{5}{|l|}{ Age } \\
\hline $15-29$ & $5188(35.4)$ & $2904(38.1)$ & 2284 (32.9) & \multirow{3}{*}{$<0.001$} \\
\hline $30-44$ & $5249(37.7)$ & $2915(37.5)$ & $2334(38.0)$ & \\
\hline 45 or more & $5475(26.9)$ & $2711(24.5)$ & $2764(29.2)$ & \\
\hline \multicolumn{5}{|l|}{ Education } \\
\hline Grade $0-7$ & $2301(15.9)$ & $1199(15.1)$ & $1102(16.7)$ & \multirow{3}{*}{0.249} \\
\hline Grade 8-11 & $5180(38.3)$ & $2822(39.2)$ & $2358(37.4)$ & \\
\hline Grade 12 or more & $6361(45.8)$ & $3411(45.8)$ & $2950(45.9)$ & \\
\hline \multicolumn{5}{|l|}{ Population group } \\
\hline African Black & 8847 (75.9) & $4832(76.1)$ & $4015(75.7)$ & \multirow{4}{*}{0.920} \\
\hline White & 2003 (11.9) & 1049 (11.9) & $954(11.9)$ & \\
\hline Coloured & $2952(9.2)$ & $1611(9.1)$ & $1341(9.3)$ & \\
\hline Indian or Asian & $2070(3.0)$ & $1024(2.9)$ & $1046(3.2)$ & \\
\hline \multicolumn{5}{|l|}{ Employment status } \\
\hline Not employed & $7221(51.5)$ & $4905(63.2)$ & $2316(40.2)$ & \multirow{2}{*}{$<0.001$} \\
\hline Employed & $7520(48.5)$ & $3109(36.8)$ & $4411(59.8)$ & \\
\hline \multicolumn{5}{|c|}{ Health status (fair or poor) } \\
\hline No & $12998(82.3)$ & $6896(81.6)$ & $6102(82.9)$ & \multirow{2}{*}{0.010} \\
\hline Yes & $2803(17.7)$ & $1567(18.4)$ & $1236(17.1)$ & \\
\hline \multicolumn{5}{|c|}{ Psychological distress $(\geq 16)$} \\
\hline No & $10212(63.8)$ & $5139(58.8)$ & $5073(68.6)$ & \multirow{2}{*}{$<0.001$} \\
\hline Yes & $5268(36.2)$ & 3155 (41.2) & $2113(31.4)$ & \\
\hline \multicolumn{5}{|c|}{ Hazardous or harmful alcohol use } \\
\hline No & $13964(87.4)$ & 8046 (95.7) & $5918(79.5)$ & \multirow{2}{*}{$<0.001$} \\
\hline Yes & $1810(12.6)$ & $406(4.3)$ & $1404(20.5)$ & \\
\hline
\end{tabular}




\begin{tabular}{lllll} 
Illicit drug use & & & & \\
No & $13876(93.8)$ & $7700(97.2)$ & $6176(90.5)$ & $<0.001$ \\
Yes & $933(6.2)$ & $267(2.8)$ & $666(9.5)$ & \\
Victim of violence crime & & & & \\
No & $14590(91.1)$ & $7949(93.3)$ & $6641(88.9)$ & $<0.001$ \\
Yes & $1254(8.9)$ & $547(6.7)$ & $707(11.1)$ & \\
Two or more sexual partners & & & & \\
No & $13103(88.6)$ & $7346(95.9)$ & $5757(81.6)$ & $<0.001$ \\
Yes & $1184(11.4)$ & $261(4.1)$ & $923(18.4)$ & \\
Sex with someone with unknown HIV status (6 ms) & & & & \\
No & $7975(72.9)$ & $4502(71.7)$ & $3473(74.2)$ & 0.194 \\
Yes & $2427(27.1)$ & $1477(28.3)$ & $950(25.8)$ & \\
\hline
\end{tabular}

\subsection{Types of Intimate Partner Violence by Age and Gender}

Among women, $5.1 \%$ had experienced physical violence (was hit) and $1.7 \%$ sexual violence in the past 12 months. Almost one in ten $(8.5 \%$ ) had experienced any form of IPV (was hit, forced sex, partner was violent against here when drunk, partner refused condom use and/or had sustained an injury) in the past 12 months. The prevalence of any IPV victimization among women was more than 10 percent in the age group 15 to 34 years and less than 4 percent in women 55 years and older. In all, $3.5 \%$ of the women had engaged in IPV perpetration $(3.0 \%$ in physical and $0.7 \%$ in sexual violence) in the past 12 months. Considering both the experience and perpetration of IPV in the past 12 months, $2.3 \%$ of the women reported probably bidirectional IPV. The proportion of women with probable bidirectional IPV was $29.5 \%$ of those with IPV victimization and $67.5 \%$ of those with IPV perpetration.

Among men, 3.7\% had experienced physical violence (was hit) and $0.9 \%$ sexual violence in the past 12 months. One in twenty (5.0\%) had experienced any form of IPV (was hit, forced sex, partner was violent against here when drunk, partner refused condom use and/or had sustained an injury). The prevalence of any IPV victimization among men was more than 5 percent in the age group 15 to 34 years and less than 1 percent in men 55 years and older. In all, $4.4 \%$ of the men had engaged in IPV perpetration (3.9\% physical and $0.9 \%$ in sexual violence) in the past 12 months. Considering both the experience and perpetration of IPV in the past 12 months, $2.7 \%$ of the men reported probably bidirectional IPV. The proportion of men with probable bidirectional IPV was $51.0 \%$ of those with IPV victimization and $58.8 \%$ of those with IPV perpetration (see Table 2).

Table 2. Types of Intimate Partner Violence by Age and Gender

\begin{tabular}{lllllll}
\hline & \multicolumn{2}{l}{ Age is years } & & & All \\
Variable & $15-24$ & $25-34$ & $35-44$ & $45-54$ & $55+$ & $\mathrm{N}(\%)$ \\
& $\mathrm{N}(\%)$ & $\mathrm{N}(\%)$ & $\mathrm{N}(\%)$ & $\mathrm{N}(\%)$ & $\mathrm{N}(\%)$ & \\
\hline Women & & & & & & \\
Was hit & $131(7.5)$ & $131(6.2)$ & $56(3.7)$ & $45(4.3)$ & $11(1.0)$ & $374(5.1)$ \\
Forced sex & $27(1.4)$ & $35(1.9)$ & $26(1.7)$ & $24(2.6)$ & $9(0.8)$ & $121(1.7)$ \\
Partner violent when drunk & $56(3.0)$ & $74(3.5)$ & $51(4.2)$ & $40(2.7)$ & $14(2.4)$ & $235(3.3)$ \\
Partner refused condom & $56(3.7)$ & $75(4.5)$ & $48(4.2)$ & $24(1.0)$ & $7(0.7)$ & $210(3.4)$ \\
Injury from partner & $11(0.6)$ & $12(0.5)$ & $8(1.0)$ & $5(0.7)$ & $3(0.3)$ & $39(0.7)$ \\
IPV victimization (any of 5) & $176(10.1)$ & $197(10.2)$ & $110(7.8)$ & $80(6.6)$ & $27(3.7)$ & $590(8.5)$ \\
I have hit a partner & $83(5.1)$ & $75(3.3)$ & $31(1.9)$ & $27(2.1)$ & $9(0.8)$ & $225(3.0)$ \\
Forced partner to have sex & $13(0.7)$ & $13(0.5)$ & $11(1.0)$ & $10(0.8)$ & $2(0.1)$ & $49(0.7)$ \\
IPV perpretration (any of 2) & $90(5.4)$ & $84(3.8)$ & $41(2.8)$ & $34(2.8)$ & $9(0.8)$ & $258(3.5)$ \\
IPV victim and perpetrator & $60(3.4)$ & $56(2.3)$ & $32(2.1)$ & $20(2.3)$ & $6(0.7)$ & $174(2.3)$ \\
\hline
\end{tabular}




\begin{tabular}{lllllll}
\hline Men & & & & & & \\
Was hit & $81(6.8)$ & $73(5.9)$ & $36(1.8)$ & $17(1.5)$ & $7(0.7)$ & $214(3.7)$ \\
Forced sex & $16(1.1)$ & $20(1.8)$ & $11(0.5)$ & $2(0.1)$ & $4(0.4)$ & $53(0.9)$ \\
Partner violent when drunk & $38(2.6)$ & $38(3.0)$ & $18(0.8)$ & $11(0.5)$ & $2(0.0)$ & $107(1.6)$ \\
Partner refused condom & $35(2.5)$ & $35(2.9)$ & $9(0.5)$ & $8(0.8)$ & $5(0.3)$ & $92(1.6)$ \\
Injury from partner & $5(0.6)$ & $4(0.5)$ & $5(0.6)$ & $1(0.1)$ & $1(0.0)$ & $16(0.4)$ \\
IPV victimization (any of 5) & $120(9.0)$ & $115(7.2)$ & $58(3.1)$ & $30(2.8)$ & $12(1.0)$ & $335(5.0)$ \\
I have hit my partner & $102(7.3)$ & $82(5.3)$ & $46(3.3)$ & $20(1.3)$ & $9(0.3)$ & $259(3.9)$ \\
Forced partner to have sex & $22(1.2)$ & $30(1.7)$ & $10(0.2)$ & $8(1.1)$ & $1(0.0)$ & $71(0.9)$ \\
$\underline{\text { IPV perpretration (any of 2) }}$ & $110(7.8)$ & $97(6.2)$ & $49(3.4)$ & $26(2.3)$ & $9(0.3)$ & $291(4.4)$ \\
IPV victim and perpetrator & $60(4.7)$ & $62(4.1)$ & $29(1.7)$ & $18(1.6)$ & $2(0.1)$ & $171(2.7)$ \\
\hline
\end{tabular}

\subsection{Association between Independent Variables and IPV Victimization and IPV Perpetration}

In multivariable logistic regression analysis among women, younger age, being African Black, having psychological distress, having been a victim of violence crime in the past 12 months and having had multiple sexual partners in the past 12 months were associated with IPV victimization in the past 12 months.

Further, younger age, having psychological distress, hazardous or harmful alcohol use, and having had multiple sexual partners in the past 12 months was associated with IPV perpetration in the past 12 months (see Table 3 ).

Table 3. Association between Sociodemographics, Health Variables and Intimate Partner Violence (IPV) victimization and perpetration among women

\begin{tabular}{|c|c|c|c|c|}
\hline \multirow[t]{3}{*}{ Variable } & \multicolumn{2}{|c|}{ IPV victimization-women } & \multicolumn{2}{|l|}{ IPV perpetration-women } \\
\hline & Unadjusted Odds & Adjusted Odds & Unadjusted Odds & Adjusted Odds \\
\hline & Ratio $(95 \% \mathrm{CI})$ & Ratio $(95 \% \mathrm{CI})$ & Ratio $(95 \% \mathrm{CI})$ & Ratio $(95 \% \mathrm{CI})$ \\
\hline \multicolumn{5}{|l|}{ Age } \\
\hline $15-29$ & 1 (Reference) & 1 (Reference) & 1 (Reference) & 1 (Reference) \\
\hline $30-44$ & $0.69(0.53,0.89)^{* *}$ & $0.72(0.51,1.01)$ & $0.50(0.31,0.79)^{* *}$ & $0.51(0.30,0.86)^{*}$ \\
\hline 45 or more & $0.46(0.32,0.66)^{* * *}$ & $0.52(0.32,0.86)^{* *}$ & $0.36(0.20,0.64)^{* * *}$ & $0.44(0.25,0.96)^{*}$ \\
\hline \multicolumn{5}{|l|}{ Education } \\
\hline Grade $0-7$ & 1 (Reference) & 1 (Reference) & 1 (Reference) & --- \\
\hline Grade 8-11 & $1.00(0.73,1.38)$ & $0.91(0.61,1.35)$ & $1.08(0.60,1.95)$ & \\
\hline Grade 12 or more & $0.60(0.41,0.86)^{* *}$ & $0.65(0.40,1.06)$ & $0.75(0.40,1.42)$ & \\
\hline \multicolumn{5}{|l|}{ Population group } \\
\hline African Black & 1 (Reference) & 1 (Reference) & 1 (Reference) & 1 (Reference) \\
\hline White & $0.16(0.08,0.33)^{* * *}$ & $0.08(0.02,0.37)^{* * *}$ & $0.24(0.09,0.64)^{* *}$ & $0.36(0.11,1.12)$ \\
\hline Coloured & $0.62(0.37,1.04)$ & $0.57(0.35,0.94)^{*}$ & $1.04(0.69,1.57)$ & $1.02(0.60,1.72)$ \\
\hline Indian or Asian & $0.07(0.04,0.13)^{* * *}$ & $0.10(0.04,0.24)^{* * *}$ & $0.13(0.06,0.28)^{* * *}$ & $0.16(0.07,0.39)^{* * *}$ \\
\hline \multicolumn{5}{|l|}{ Employment status } \\
\hline Not employed & 1 (Reference) & 1 (Reference) & 1 (Reference) & --- \\
\hline Employed & $0.75(0.58,0.98)^{*}$ & $1.03(0.62,1.68)$ & $0.92(0.59,1.43)$ & \\
\hline \multicolumn{5}{|c|}{ Health status (fair or poor) } \\
\hline No & 1 (Reference) & 1 (Reference) & 1 (Reference) & 1 (Reference) \\
\hline Yes & $1.46(1.09,1.97)^{*}$ & $1.26(0.85,1.88)$ & $1.72(1.09,2.71)^{*}$ & $1.46(0.83,2.56)$ \\
\hline
\end{tabular}




\begin{tabular}{|c|c|c|c|c|}
\hline \multicolumn{5}{|c|}{ Psychological distress $(\geq 16)$} \\
\hline No & 1 (Reference) & 1 (Reference) & 1 (Reference) & 1 (Reference) \\
\hline Yes & $2.20(1.68,2.88)^{* * *}$ & $1.64(1.13,2.37)^{* *}$ & $3.82(2.51,5.81)^{* * *}$ & $3.17(1.99,5.07)^{* * *}$ \\
\hline \multicolumn{5}{|c|}{$\begin{array}{l}\text { Hazardous or harmful alcohol } \\
\text { use }\end{array}$} \\
\hline No & 1 (Reference) & 1 (Reference) & 1 (Reference) & 1 (Reference) \\
\hline Yes & $3.22(2.17,4.47)^{* * *}$ & $1.46(0.87,2.44)$ & $4.54(2.57,7.71)^{* * *}$ & $2.42(1.06,5.52)^{*}$ \\
\hline \multicolumn{5}{|c|}{ Illicit drug use } \\
\hline No & 1 (Reference) & 1 (Reference) & 1 (Reference) & 1 (Reference) \\
\hline Yes & $2.01(1.11,3.64)^{*}$ & $1.78(0.78,4.07)$ & $2.71(1.21,6.07)^{*}$ & $1.92(0.81,4.54)$ \\
\hline \multicolumn{5}{|c|}{ Victim of violence crime } \\
\hline No & 1 (Reference) & 1 (Reference) & 1 (Reference) & 1 (Reference) \\
\hline Yes & $2.67(1.83,3.88)^{* * *}$ & $3.04(1.73,5.33)^{* * *}$ & $2.27(1.17,4.39)^{*}$ & $2.11(0.87,5.11)$ \\
\hline \multicolumn{5}{|c|}{ Two or more sexual partners } \\
\hline No & 1 (Reference) & 1 (Reference) & 1 (Reference) & 1 (Reference) \\
\hline Yes & $3.55(2.09,6.03)^{* * *}$ & $2.69(1.49,4.86)^{* * *}$ & $2.63(1.43,4.81)^{* *}$ & $1.91(1.01,3.61)^{*}$ \\
\hline \multicolumn{5}{|c|}{$\begin{array}{l}\text { Sex with someone with } \\
\text { unknown HIV status }(6 \mathrm{~ms})\end{array}$} \\
\hline No & 1 (Reference) & 1 (Reference) & 1 (Reference) & --- \\
\hline Yes & $1.82(1.32,2.51)^{* * *}$ & $1.16(0.80,1.69)$ & $1.25(0.73,2.11)$ & \\
\hline
\end{tabular}

$* * * \mathrm{P}<0.001 ; * * \mathrm{P}<0.01 ; * \mathrm{P}<0.05 ; \mathrm{CI}=$ Confidence Interval

In multivariable logistic regression analysis among men, younger age, having psychological distress, hazardous or harmful alcohol use, and having been a victim of violence crime in the past 12 months were associated with IPV victimization in the past 12 months.

Further, younger age, poor health status, having psychological distress, hazardous or harmful alcohol use, and illicit drug use was associated with IPV perpetration in the past 12 months (see Table 4).

Table 4. Association between Sociodemographics, Health Variables and Intimate Partner Violence (IPV) victimization and perpetration among men

\begin{tabular}{|c|c|c|c|c|}
\hline \multirow[b]{2}{*}{ Variable } & \multicolumn{2}{|l|}{ IPV victimization-men } & \multicolumn{2}{|l|}{ IPV perpetration-men } \\
\hline & $\begin{array}{l}\text { Unadjusted Odds Ratio } \\
(95 \% \mathrm{CI})\end{array}$ & $\begin{array}{l}\text { Adjusted Odds Ratio } \\
(95 \% \mathrm{CI})\end{array}$ & $\begin{array}{l}\text { Unadjusted Odds } \\
\text { Ratio }(95 \% \mathrm{CI})\end{array}$ & $\begin{array}{l}\text { Adjusted Odds Ratio } \\
(95 \% \mathrm{CI})\end{array}$ \\
\hline \multicolumn{5}{|l|}{ Age } \\
\hline $15-29$ & 1 (Reference) & 1 (Reference) & 1 (Reference) & 1 (Reference) \\
\hline $30-44$ & $0.49(0.33,0.72)^{* * *}$ & $0.50(0.27,0.91)^{*}$ & $0.57(0.36,0.80)^{* *}$ & $0.62(0.39,0.98)^{*}$ \\
\hline 45 or more & $0.21(0.12,0.36)^{* * *}$ & $0.47(0.19,1.19)$ & $0.18(0.10,0.32)^{* * *}$ & $0.30(0.15,0.61)^{* * *}$ \\
\hline \multicolumn{5}{|l|}{ Education } \\
\hline Grade $0-7$ & 1 (Reference) & 1 (Reference) & 1 (Reference) & \\
\hline Grade 8-11 & $2.00(1.06,3.80)^{*}$ & $1.36(0.59,3.13)$ & $1.16(0.63,2.16)$ & --- \\
\hline Grade 12 or more & $1.31(0.69,2.48)$ & $1.17(0.52,2.67)$ & $0.66(0.35,1.26)$ & \\
\hline \multicolumn{5}{|l|}{ Population group } \\
\hline African Black & 1 (Reference) & 1 (Reference) & 1 (Reference) & 1 (Reference) \\
\hline
\end{tabular}




\begin{tabular}{|c|c|c|c|c|}
\hline White & $0.18(0.08,0.40)^{* * *}$ & $0.29(0.07,1.14)$ & $0.14(0.04,0.56)^{* *}$ & $0.07(0.02,0.25)^{* * *}$ \\
\hline Coloured & $0.82(0.54,1.24)$ & $0.96(0.54,1.69)$ & $0.70(0.46,1.06)$ & $0.69(0.43,1.10)$ \\
\hline Indian or Asian & $0.21(0.10,0.44)^{* * *}$ & $0.16(0.06,0.43)^{* * *}$ & $0.23(0.10,0.52)^{* * *}$ & $0.40(0.16,1.00)$ \\
\hline \multicolumn{5}{|l|}{ Employment status } \\
\hline Not employed & 1 (Reference) & --- & 1 (Reference) & \multirow{2}{*}{---} \\
\hline Employed & $0.88(0.62,1.25)$ & & $0.87(0.59,1.28)$ & \\
\hline \multicolumn{5}{|l|}{$\begin{array}{l}\text { Health status (fair or } \\
\text { poor) }\end{array}$} \\
\hline No & 1 (Reference) & 1 (Reference) & 1 (Reference) & 1 (Reference) \\
\hline Yes & $1.93(1.26,2.96)^{* *}$ & $1.67(0.84,3.32)$ & $1.80(1.15,2.83)^{* *}$ & $1.99(1.15,3.44)^{*}$ \\
\hline \multicolumn{5}{|l|}{$\begin{array}{l}\text { Psychological distress } \\
(\geq 16)\end{array}$} \\
\hline No & 1 (Reference) & 1 (Reference) & 1 (Reference) & 1 (Reference) \\
\hline Yes & $3.09(2.04,4.68)^{* * *}$ & $2.17(1.30,3.60)^{* *}$ & $2.96(1.99,4.40)^{* * *}$ & $2.21(1.43,3.42)^{* * *}$ \\
\hline \multicolumn{5}{|l|}{$\begin{array}{l}\text { Hazardous or harmful } \\
\text { alcohol use }\end{array}$} \\
\hline No & 1 (Reference) & 1 (Reference) & 1 (Reference) & 1 (Reference) \\
\hline Yes & $5.70(4.17,7.79)^{* * *}$ & $2.42(1.40,4.18)^{* *}$ & $4.01(2.75,5.85)^{* * *}$ & $2.22(1.46,3.37)^{* * *}$ \\
\hline \multicolumn{5}{|l|}{ Illicit drug use } \\
\hline No & 1 (Reference) & 1 (Reference) & 1 (Reference) & 1 (Reference) \\
\hline Yes & $3.82(2.56,5.69)^{* * *}$ & $1.36(0.72,2.59)$ & $3.86(2.50,5.96)^{* * *}$ & $2.33(1.50,3.62)^{* * *}$ \\
\hline \multicolumn{5}{|l|}{ Victim of violence crime } \\
\hline No & 1 (Reference) & 1 (Reference) & 1 (Reference) & \multirow{2}{*}{---} \\
\hline Yes & $2.61(1.66,4.10)^{* * *}$ & $2.20(1.03,4.70)^{*}$ & $1.45(0.83,2.51)$ & \\
\hline \multicolumn{5}{|l|}{$\begin{array}{l}\text { Two or more sexual } \\
\text { partners }\end{array}$} \\
\hline No & 1 (Reference) & 1 (Reference) & 1 (Reference) & 1 (Reference) \\
\hline Yes & $3.15(2.18,4.56)^{* * *}$ & $1.36(0.80,2.32)$ & $2.92(1.98,4.31)^{* * *}$ & $1.35(0.82,2.22)$ \\
\hline \multicolumn{5}{|l|}{$\begin{array}{l}\text { Sex with someone with } \\
\text { unknown HIV status ( } 6 \\
\text { ms) }\end{array}$} \\
\hline No & 1 (Reference) & 1 (Reference) & 1 (Reference) & \multirow{2}{*}{--- } \\
\hline Yes & $1.65(1.09,2.50)^{*}$ & $1.05(0.53,2.08)$ & $1.60(1.00,2.56)^{*}$ & \\
\hline \multicolumn{5}{|l|}{ HIV status } \\
\hline Negative & 1 (Reference) & --- & 1 (Reference) & \multirow{2}{*}{--- } \\
\hline Positive & $0.98(0.54,1.78)$ & & $1.39(0.79,2.45)$ & \\
\hline
\end{tabular}

$* * * \mathrm{P}<0.001 ; * * \mathrm{P}<0.01 ;{ }^{*} \mathrm{P}<0.05 ; \mathrm{CI}=$ Confidence Interval

\section{Discussion}

In this 2012, nationally representative sample of individuals 15 years and older in South Africa, $8.5 \%$ of women and $5.0 \%$ of men had experienced IPV victimization in the past 12 months. The figure for women IPV victimization was pretty similar to the 2016 Demographic and Health Survey in South Africa (Statistics South Africa, 2017) and other previous studies in South Africa (e.g., Jewkes, Penn-Kekana, Levin, Ratsaka, \& Schrieber, 2001), but the figures for both women and men seem to be lower than in a national population-based survey for the "current or most recent marriage or cohabiting relationship" in South Africa in 2002-2004 (29.3\% among women 
and $20.9 \%$ among men) (Gass et al., 2011). The latter higher figures may explained by the potentially lifetime IPV rather than 12-month prevalence.

Further, the study found a 12-month IPV perpetration prevalence of 3.5\% among women and $4.4 \%$ among men. Previous studies in South Africa and elsewhere (Fleming et al., 2015; Gass et al., 2011; Peitzmeier et al., 2016) seem to have found higher rates of IPV perpetration, although lifetime rates were reported that are difficult to comapre with 12-month rates. The study also found high rates of co-occurrence of IPV victimization and perpetration, especially among IPV perpetrators, among both women and men. Similar results were found in a previous study in Tanzania (Mulawa et al., 2016). Although this study could not establish if IPV perpetration and victimization had happened within the same intimate relationship, a high probability of such overlap can be assumed given the 12 months reference period suggesting bidirectional IPV (Mulawa et al., 2016).

In agreement with some previous studies (Gass et al., 2011; Statistics South Africa, 2017), this study found that women at a younger age were more likely to report IPV victimization than men, and men were more likely to report IPV perpetration than women. Only in bivariate analysis among women lower education level and unemployment, as found previously (Heise \& Kotsadam, 2015; WHO, 2016), was associated with IPV victimization in this study.

In agreement with previous studies (Gass et al., 2011; Gonzalez et al., 2014; Peitzmeier et al. 2016; WHO, 2016) harmful use of alcohol was associated with IPV perpetration and experience among men and IPV perpetration among women, and illicit drug use was in multivariable analysis associated with PIV perpetration among men and in bivariate analysis associated with IPV experiences and perpetration among women and IPV victimization in men. In a recent review, Rivera et al. (2015) found that in most studies a bidirectional relationship existed between IPV and substance use disorders.

This study found, in agreement with previous studies (Fleming et al. 2015; Gass et al., 2011, Ishida et al., 2010; Peitzmeier et al. 2016), an association common mental disorders and/or community violence victimization with IPV victimization and/or perpetration among women and/or men. However, contrary to these study findings common mental disorders have commonly been seen as a sequela of IPV, and not as a risk factor (Gass et al., 2011) Considering the importance of common mental disorders and its links to all type of IPV experiences and perpetration both among women and men in this study, further research is suggested to gain better insight into gender differentials of poor mental health as risk factor of IPV and sequela of IPV (Gass et al., 2011). Some studies (e.g., Tsai, Tomlinson, Comulada, \& Rotheram-Borus, 2016), also found a bidirectional relationship between IPV and depression among women in South Africa.

Previous studies (WHO, 2016) found that having multiple partners was correlated with IPV perpetration among men, but this study found that having multiple sexual partners was associated with IPV experience and perpetration among women, and only in bivariate analysis among men. In bivariate analysis having sex with someone with unknown HIV, status was associated with IPV experience among women and men, and IPV perpetration among men.

\subsection{Study limitation}

This study had several limitations. Since this was a cross-sectional survey, we cannot establish causality between certain variables and IPV. Responses on IPV experiences and perpetration were based on self-report and social desirability biases may have led to underreporting of IPV. A further limitation of this study was that certain relevant concepts linked with IPV, such as "exposure to child maltreatment; witnessing family violence; antisocial personality disorder; and attitudes that are accepting of violence and gender inequality (perpetration and experience)" (Gass et al., 2011; WHO, 2016), were not assessed and should be included in future studies.

\section{Conclusion}

Past 12-month prevalence of IPV victimization and perpetration among both women and men was significant. IPV gender commonalities and differences in risk factors, such as psychological distress, substance use, crime victimization and sexual risk behaviour, may inform strategies of violence prevention programmes. Interventions targeting women may include management of psychological distress, reduction of alcohol use, crime prevention and safer sexual practices, and interventions targeting men may include management of psychological distress, alcohol abuse, illicit drug use, crime prevention and improvement of health status. Future research should focus on understanding the complex processes involved in the development of IPV victimization and perpetration, such as childhood exposure to various forms of violence, including witnessing and structural violence. 


\section{Acknowledgements}

The work used data from the "Human Sciences Research Council. South African National HIV Prevalence, HIV Incidence, Behaviour and Communication Survey (SABSSM) 2012: Combined - All provinces. [Data set]. SABSSM 2012 Combined. Version 1.0. Pretoria South Africa: Human Sciences Research Council [producer] 2013, Human Sciences Research Council [distributor] 2016. http://dx.doi.org/doi:10.14749/1485430466.” The original study was supported by the "USA's Centers for Disease control and Prevention and the Human Sciences Research Council, the Bill \& Melinda Gates Foundation, the United Nations Children's Fund, and the South African National AIDS Council.”

\section{Conflict of Interest}

The authors declare that they have no conflict of interest in regards to the publication of this paper.

\section{References}

Andersen, L. S., Grimsrud, A., Myer, L., Williams, D. R., Stein, D. J., \& Seedat, S. (2011). The psychometric properties of the K10 and K6 scales in screening for mood and anxiety disorders in the South African Stress and Health study. International Journal of Methods in Psychiatric Research, 20(4), 215-223. https://doi.org/10.1002/mpr.351

Babor, T. F., Higgins-Biddle, J. C., Saunders, J. B., \& Monteiro, M. G. (2001). AUDIT: The Alcohol Use Disorders Identification Test. Guidelines for use in primary care. Geneva, Switzerland: World Health Organization.

Breiding, M. J., Smith, S. G., Basile, K. C., Walters, M. L., Chen, J., \& Merrick, M. T. (2014). Prevalence and characteristics of sexual violence, stalking, and intimate partner violence victimization--national intimate partner and sexual violence survey, United States, 2011. Morbidity and Mortality Weekly Report Surveillance Summaries, 63(8), 1-18.

Campbell, J. C. (2002). Health consequences of intimate partner violence. Lancet, 359, 1331-6. https://doi.org/10.1016/S0140-6736(02)08336-8

Ellsberg, M., Jansen, H. A., Heise, L., Watts, C. H., Garcia-Moreno, C., \& WHO Multi-country Study on Women's Health and Domestic Violence against Women Study Team. (2008). Intimate partner violence and women's physical and mental health in the WHO multi-country study on women's health and domestic violence: An observational study. Lancet, 371, 1165e72. https://doi.org/10.1016/S0140-6736(08)60522-X

Fleming, P. J., McCleary-Sills, J., Morton, M., Levtov. R., Heilman, B., \& Barker, G. (2015). Risk factors for men's lifetime perpetration of physical violence against intimate partners: results from the international men and gender equality survey (IMAGES) in eight countries. PLoS One, 10(3), e0118639. https://doi.org/10.1371/journal.pone.0118639

Gass, J. D., Stein, D. J., Williams, D. R., \& Seedat, S. (2011). Gender differences in risk for intimate partner violence among South African adults. Journal of Interpersonal Violence, 26(14), 2764-89. https://doi.org/10.1177/0886260510390960

Gonzalez, J. M., Connell, N. M., Businelle, M. S., Jennings, W. G., \& Chartier. K. G. (2014). Characteristics of adults involved in alcohol-related intimate partner violence: results from a nationally representative sample. BMC Public Health, 14, 466. https://doi.org/10.1186/1471-2458-14-466

Heise, L. L., \& Kotsadam, A. (2015). Cross-national and multilevel correlates of partner violence: an analysis of data from population-based surveys. Lancet Global Health, 3(6), e332-40. https://doi.org/10.1016/S2214-109X(15)00013-3

Humeniuk, R. E., Henry-Edwards, S., Ali, R. L., Poznyak, V., \& Monteiro, M. (2010). The Alcohol, Smoking and Substance Involvement Screening Test (ASSIST): manual for use in primary care. Geneva, Switzerland: World Health Organization.

Ishida, K., Stupp, P., Melian, M., Serbanescu, F., \& Goodwin, M. (2010). Exploring the associations between intimate partner violence and women's mental health: evidence from a population-based study in Paraguay. Social Science and Medicine, 71(9), 1653-61. https://doi.org/10.1016/j.socscimed.2010.08.007

Jewkes, R., Penn-Kekana, L., Levin, J., Ratsaka, M., \& Schrieber, M. (2001). Prevalence of emotional, physical and sexual abuse of women in three South African provinces. South African Medical Journal, 91(5), 421-8.

Kessler, R. C., Barker, P. R., Colpe, L. J., Epstein, J. F., Gfroerer, J. C., Hiripi, E., ... Zaslavsky, A. M. (2003). Screening for serious mental illness in the general population. Archives of General Psychiatry, 60(2), 
184e-189e. https://doi.org/10.1001/archpsyc.60.2.184

Mulawa, M., Kajula, L. J., Yamanis, T. J., Balvanz, P., Kilonzo, M. N., \& Maman, S. (2016). Perpetration and victimization of intimate partner violence among young men and women in Dar es Salaam, Tanzania. Journal of Interpersonal Violence. pii: 0886260515625910. https://doi.org/10.1177/0886260515625910

Peitzmeier, S. M., Kågesten, A., Acharya, R., Cheng, Y., Delany-Moretlwe, S., Olumide A, ..., Decker, M. R. (2016). Intimate partner violence perpetration among adolescent males in disadvantaged neighborhoods globally. Journal of Adolescent Health, 59(6), 696-702. https://doi.org/10.1016/j.jadohealth.2016.07.019

Rivera, E. A., Phillips, H., Warshaw, C., Lyon, E., Bland, P. J., Kaewken, O. (2015). An applied research paper on the relationship between intimate partner violence and substance use. Chicago, IL: National Center on Domestic Violence, Trauma \& Mental Health.

Seedat, M., Van Niekerk, A., Jewkes, R., Suffla, S., \& Ratele, K. (2009). Violence and injuries in South Africa: prioritising an agenda for prevention. Lancet, 374, 1011-1022. https://doi.org/10.1016/S0140-6736(09)60948-X

Shisana, O., Rehle, T., Simbayi, L. C., Zuma, K., Jooste, S., Zungu, N., ..., Onoya, D. (2014). South African national HIV prevalence, incidence and behaviour survey, 2012. Cape Town: HSRC Press.

Statistics South Africa (2017). South Africa Demographic and Health Survey 2016: Key Indicator Report. Pretoria: Statistics South Africa.

Tsai, A. C., Tomlinson, M., Comulada, W. S., \& Rotheram-Borus, M. J. (2016). Intimate partner violence and depression symptom severity among South African women during pregnancy and postpartum: population-based prospective cohort study. PLoS Medicine, 13(1), e1001943. https://doi.org/10.1371/journal.pmed.1001943

World Health Organization (WHO). (2013). Global and regional estimates of violence against women: Prevalence and health effects of intimate partner violence and non-partner sexual violence. Geneva, Switzerland: World Health Organization.

World Health Organization (WHO). (2016). Violence against women, Intimate partner and sexual violence against women, Fact sheet. Retrieved 28 May, 2017, from http://www.who.int/mediacentre/factsheets/fs239/en/

\section{Copyrights}

Copyright for this article is retained by the author(s), with first publication rights granted to the journal.

This is an open-access article distributed under the terms and conditions of the Creative Commons Attribution license (http://creativecommons.org/licenses/by/4.0/). 